\title{
MicroRNA as a Molecular Marker for Predicting the Risk of Intestinal Type Gastric Cancer Development
}

\author{
DOI: $10.17691 / \mathrm{stm} 2018.10 .2 .18$
}

Received October 27, 2017

V.A. Rubtsov, PhD Student, Department of Pathological Anatomy';

Y.A. Fedotova, Senior Teacher, Department of Pathological Anatomy';

M.K. Ivanov, PhD, Head of PCR Laboratoty2;

S.E. Titov, Researcher, PCR Laboratoty2;

E.G. Pomorgailo, DSc, Professor, Department of Pathological Anatomy ${ }^{1}$

${ }^{1}$ Omsk State Medical University, 12 Lenin St., Omsk, 644099, Russia;

${ }^{2}$ Vector-Best, P.O. Box492, Novosibirsk, 630117, Russia

The aim of the study was to assess expression of microRNAs (miRNAs) influencing the key carcinogenesis pathways in the tissues of gastric mucosa in patients with H. pylori-associated chronic gastritis and gastric cancer of intestinal type (directly in the tumor tissue and mucosa of the stomach with morphological signs of chronic gastritis).

Materials and Methods. Objects of investigations were fragments of gastric mucosa of the antral part of the stomach with $H$. pyloriassociated chronic gastritis: 10 were bioptates with minimal changes, 9 bioplates with chronic gastritis, and specimens of surgical material taken from the stomachs with gastric cancer of intestinal type: 28 were tumor fragments and 22 the tissue from the sites beyond tumor growth (chronic atrophic gastritis). The number of miRNAs miR-146a, miR-155, miR-21, miR-223, miR-192, miR-200b, miR-221, miR-375 in paraffin sections was determined by a real-time semi-quantitative hairpin RT-PCR assay.

Results. The analysis of miR-21 and miR-223 showed the most statistically significant results among the investigated miRNAs. The expression level of oncogenic miR-21 and miR-223 significantly and successively increases in the range of the examined diseases from H. pylori-associated chronic gastritis to intestinal type gastric adenocarcinoma.

Conclusion. MiRNAs miR-21 and miR-223 may be considered as perspective biomarkers for assessing the risk of development, early diagnosis, and prognosis of intestinal type gastric cancer.

Key words: microRNA; miR-21; miR-223; gastric cancer of intestinal type; molecular markers.

\section{Introduction}

The most common form of gastric cancer, adenocarcinoma of intestinal type, arises in presence of persistent inflammation of gastric mucosa leading to atrophic gastritis following by intraepithelial neoplasia and invasive stomach cancer of intestinal type [1, 2]. A frequent cause of chronic gastritis is bacterium Helicobacter pylori (H. pylori). Chronic gastritis and early forms of tumor growth are not always clinically manifested and therefore gastric cancer is often identified at stage III-IV and in more than $75 \%$ of cases treatment is possible only as a palliative operation and chemotherapy [3]. The development of methods for early diagnosis and search for predictors of stomach cancer are therefore of vital importance. Perspective candidates for the role of gastric cancer predictors are microRNAs (miRNAs) representing noncoding ribonucleic acids which consist on average of 22 nucleotides. Binding with 3'-UTR matrix RNA of target genes on the principle of full or partial complementarity, ribonucleotide complexes including miRNA destroy matrix RNA or inhibit its translation, respectively, and due to this, gene expression is posttranscriptionally regulated by miRNAs. Owing to this mechanism, miRNAs participate in proliferation, differentiation [4], and apoptosis of the cells [5], the processes playing a key role in pathogenesis of many diseases including oncological [6, 7]. Aberrant expression of miRNAs has been shown in many malignant tumors [8]. Despite active investigations of miRNA expression in gastric cancer, data on their level changes in the tissues of gastric mucosa at the early stages of carcinogenesis remain insufficient and therefore require further exploration.

The aim of the study was to assess expression of miRNAs influencing the key carcinogenesis pathways in the tissues of gastric mucosa in patients with $\mathrm{H}$. pyloriassociated chronic gastritis and gastric cancer of intestinal type (directly in the tumor tissue and mucosa of the stomach with morphological signs of chronic gastritis).

Corresponding author: Vyacheslav A. Rubtsov, e-mail: sl1zig1@rambler.ru 


\section{Materials and Methods}

The objects of investigations were fragments of gastric mucosa of the antral part of the stomach with H. pylori-associated chronic gastritis: 10 were bioptates with minimal changes (group 1, control), 9 bioplates with chronic gastritis (group 2), and specimens of surgical material taken from the stomachs with gastric cancer of intestinal type among which 22 (group 3) were the tissue taken from the sites beyond the tumor growth (chronic atrophic gastritis) and 28 were tumor fragments (group 4).

The present study complies with the Declaration of Helsinki (2013) and was approved by the Ethics Committee of Omsk State Medical University. Written informed consent was obtained from every patient.

Fragments of the examined tissues were fixed in $10 \%$ neutral buffered formalin solution ( $\mathrm{pH} \mathrm{7.2-7.4)} \mathrm{for} \mathrm{12-}$ $24 \mathrm{~h}$. Preparation of the material, embedding in paraffin, and obtaining paraffin sections was performed according to the standard procedure. Morphological alterations of the gastric mucosa were assessed by the histological preparations stained with hematoxylin and eosin.

Molecules, whose role in carcinogenesis of gastric cancer was reported in previous investigations, were chosen among miRNAs [9]: miR-146a, miR-155, miR-21, miR-223, miR-192, miR-200b, miR-221, miR-375. Quantification of miRNA expression in the paraffin sections was assessed using real-time semiquantitative hairpin RT-PCR assay with specific primers for the analyzed miRNAs. Normalization was performed in accordance with the standard method, i.e. to a small nuclear U6 RNA.

Mann-Whitney $U$ test for two independent samples (the main groups and a comparative group) was used as the main characteristics of descriptive statistics of numeric data. A critical level of significance in testing statistical hypotheses was assumed to be equal to $\mathrm{p} \leq 0.05$.

\section{Results}

Significant and successive increase of expression of all analyzed miRNA in examined groups was noted: $H$. pylori-associated chronic nonatrophic gastritis (group 2), atrophic gastritis (group 3), intestinal type gastric adenocarcinoma (group 4) in comparison with the control group of bioptates with minimally changed gastric mucosa. An exclusion was oncosuppressive miR375 whose expression in stomach cancer is normally downregulated (Table 1).

Among the examined miRNAs, the most statistically significant results $(p<0.01)$ in all groups were revealed in the analysis of miR-21and miR-223 expression (see the Figure).

\section{Discussion}

Alteration of miRNA expression starts already at the stage of $H$.pylori-associated chronic gastritis: this bacterium colonizing the mucosa of the stomach both directly $[10,11]$ and indirectly (due to chronic inflammation) [12] causes alterations in the expression of many miRNAs. Virulence factors of $H$. pylori, the main of which are CagA, VacA, IceA, BabA, SabA, DupA [13], affect essentially the most important regulatory pathways of vital activity of gastric mucous epithelial cells. CagA induces the increase of IL-1 $1 \beta$, IL-8 protein production and activation of NF-kB which is associated with pro-inflammatory cytokine production and cell apoptosis, impairs regulation of cell signaling pathways, and promotes carcinogenesis [14]. VacA increases production of TNF- $\alpha$, IL-1 $1 \beta$, nitrogen oxide, active forms of oxygen, and activation of NF-KB. Virulence factors and pro-inflammatory cytokines cause changes in miRNA expression [15]. Aberrant expression of miRNAs in turn influences the expression of protein target genes from the key signaling pathways playing a great role in initiation and progressive development of gastric cancer [16].

Table 1

Relative expression levels of microRNAs in the examined groups $(M \pm m)$

\begin{tabular}{|lcccc|}
\hline MicroRNA & $\begin{array}{c}\text { Gastric mucosa } \\
\text { with minimal } \\
\text { alterations } \\
\text { (group 1) }\end{array}$ & $\begin{array}{c}\text { H. pylori-associated } \\
\text { chronic gastritis } \\
\text { (group 2) }\end{array}$ & $\begin{array}{c}\text { Chronic atrophic } \\
\text { gastritis beyond } \\
\text { the tumor growth } \\
\text { (group 3) }\end{array}$ & $\begin{array}{c}\text { Intestinal type } \\
\text { gastric cancer } \\
\text { (group 4) }\end{array}$ \\
\hline miR-21 & $5.54 \pm 0.93$ & $55.76 \pm 9.85$ & $225.69 \pm 39.96$ & $378.65 \pm 35.41$ \\
\hline miR-223 & $-10.96 \pm 5.30$ & $12.40 \pm 5.59$ & $84.60 \pm 22.43$ & $114.09 \pm 38.56$ \\
\hline miR-375 & $1.64 \pm 0.58$ & $15.03 \pm 2.90$ & $37.58 \pm 7.47$ & $13.94 \pm 2.53$ \\
\hline miR-146a & $-15.05 \pm 6.28$ & $1.18 \pm 0.83$ & $3.82 \pm 1.23$ & $3.90 \pm 0.85$ \\
\hline miR-155 & $-165.31 \pm 31.16$ & $-16.56 \pm 4.34$ & $-8.72 \pm 2.08$ & $-8.26 \pm 1.31$ \\
\hline miR-221 & $-46.88 \pm 6.95$ & $-4.02 \pm 0.50$ & $0.64 \pm 0.72$ & $1.66 \pm 1.24$ \\
\hline miR-192 & $1.04 \pm 0.58$ & $19.91 \pm 5.01$ & $37.70 \pm 8.02$ & $38.46 \pm 7.53$ \\
\hline miR-200b & $2.70 \pm 0.24$ & $30.36 \pm 7.08$ & $40.57 \pm 4.76$ & $42.93 \pm 8.13$ \\
\hline
\end{tabular}




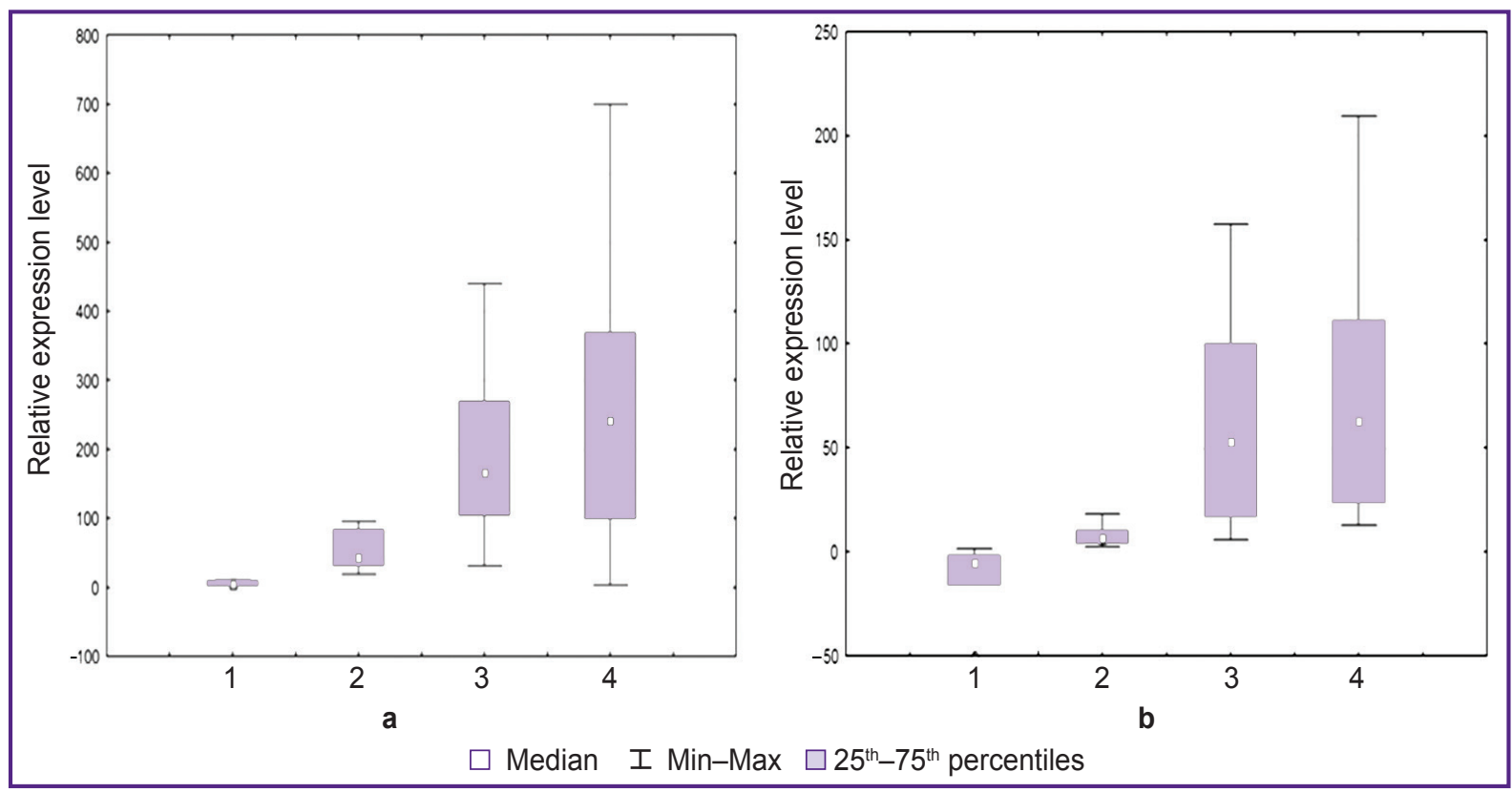

Relative levels of miR-21 (a) and miR-223 (b) expression in the specimens of gastric mucosa tissues:

(1) gastric mucosa with minimal alterations; (2) H. pylori-associated chronic gastritis; (3) distant zone (beyond the tumor growth): chronic atrophic gastritis; (4) intestinal type gastric cancer

Table 2

Target genes and biological effects of microRNAs miR-21, miR-223, miR-375

\begin{tabular}{lcl}
\hline \multicolumn{1}{c}{ MicroRNA } & Target genes & \multicolumn{1}{c}{ Regulated biological process } \\
miR-21 (upregulated in gastric cancer) & PTEN, TGFBR1, TGFBR2, PDCD4 & Cell proliferation \\
\cline { 2 - 3 } miR-223 (upregulated in gastric cancer) & RECK & $\begin{array}{l}\text { Invasion and metastasis due to activation } \\
\text { of metalloproteinases MMP-2, MMP-9, and MMP14 }\end{array}$ \\
miR-375 (downregulated in gastric cancer) & EPB41L3, E2F1, FOX01, NFI-A & Cell proliferation, migration, and invasion \\
\cline { 2 - 3 } & 14-3-3zeta & Apoptosis caspase pathway \\
\hline
\end{tabular}

Statistically significantly higher levels of miR-21, miR-223 expression found during our investigation in the fragments of mucosa from the stomachs resected for intestinal type adenocarcinoma and those beyond the tumor growth (with a histological picture of chronic atrophic gastritis) compared to the specimens with the similar histological picture but without association with gastric cancer (miR-21: $p=0.00046$; miR-223: $p=0.00119$ ) allow us to consider these miRNAs as the markers of gastric cancer risk development. At the same time, statistically significant differences between the expressions of these miRNAs in the pairs of "gastric adenocarcinoma-chronic atrophic gastritis beyond the tumor growth" in the mucosa of the resected stomach have not been found. miRNA miR-21, which is significantly upregulated in the gastric mucosa in $H$. pylori infection, activates proliferation owing to its direct target PTEN (from PI3K-Akt signaling pathway) [17], and blocks apoptosis by PDCD4 gene regulation [5]. miR-223 are associated with invasion and metastasizing due to the expression of genes EPB41L3, FBXW7, HCDC4, STMN1 [18]. Molecules miR-375, expression of which is downregulated in the tissues in gastric cancer due to hyperproduction of IL-6, IL-8 and TNF- $\alpha$ in chronic inflammation (due to the target - Sp1 and JAJ2 from the signaling pathways PI3K-Akt-Sp1 and JAK2-STAT3, respectively), prevent invasion and metastasizing [19]. The most significant target genes miR-21, miR-223, miR-375, and biological effects connected with their regulation because of alterations in miRNA expression are presented in Table 2.

Thus, the expression level of oncogenic miRNAs miR21 and miR-223 increases significantly and successively in the range of the examined pathologies from $H$. pyloriassociated atrophic gastritis to gastric adenocarcinoma of intestinal type speaking of the important role of these miRNAs in carcinogenesis of gastric cancer. Data obtained in comparing miRNA expression in the 
tissues of adenocarcinoma and a distant zone (beyond the tumor growth) are most likely to be considered as a confirmation of a theory of tumor field effect and metachronous cancer with multifocal initiation and subsequent spontaneous promotion and progression in one of these areas, preserving aberrations and the pattern of miRNA expression in other areas.

\section{Conclusion}

MicroRNAs miR-21 and miR-223may be considered perspective biomarkers for assessing the risk of development and early diagnosis of intestinal type gastric cancer.

Study funding. The work was performed within the frames of the State assignment, state registration No.115031760046 of 17.03.2015.

Conflicts of interests. The authors have no conflicts of interest to declare.

\section{References}

1. Merabishvili V.M. Analytical epidemiology of gastric cancer. Voprosy onkologii 2013; 59(5): 565-570.

2. Rugge M., Genta R.M., Graham D.Y., Mario F., Coelho L.G., Kim N., Malfertheiner P., Sugano K., Tsukanov V., Correa P. Chronicles of a cancer foretold: 35 years of gastric cancer risk assessment. Gut 2016; 65(5): 721-725, https://doi. org/10.1136/gutjnl-2015-310846.

3. Fletcher C.D.M. Diagnostic histopathology of tumors. Philadelphia: Elsevier; 2013. 2296 p.

4. Haneklaus M., Gerlic M., O'Neill L.A., Masters S.L. miR223: infection, inflammation and cancer. J Intern Med 2013; 274(3): 215-226, https://doi.org/10.1111/joim.12099.

5. Zhang Z., Li Z., Gao C., Chen P., Chen J., Liu W., Xiao S., Lu H. miR-21 plays a pivotal role in gastric cancer pathogenesis and progression. Lab Invest 2008; 88(12): 1358 1366, https://doi.org/10.1038/labinvest.2008.94.

6. Farazi T.A., Hoell J.I., Morozov P., Tuschl T. MicroRNAs in human cancer. Adv Exp Med Biol 2013; 774: 1-20, https:// doi.org/10.1007/978-94-007-5590-1_1.

7. Nikitina E.G., Urazova L.N., Stegny V.N. MicroRNAs and human cancer. Exp Oncol 2012; 34(1): 2-8.

8. Esquela-Kerscher A., Slack F.J. Oncomirs microRNAs with a role in cancer. Nat Rev Cancer 2006; 6(4): 259-269, https://doi.org/10.1038/nrc1840.

9. Shrestha S. Hsu S.D., Huang W.Y., Huang H.Y., Chen W. Weng S.L., Huang H.D. A systematic review of
microRNA expression profiling studies in human gastric cancer. Cancer Med 2014; 3(4): 878-888, https://doi.org/10.1002/ cam4.246.

10. Feng Y., Wang L., Zeng J., Shen L., Liang $X$., Yu H., Liu S., Liu Z., Sun Y., Li W., Chen C., Jia J. FoxM1 is overexpressed in Helicobacter pylori-induced gastric carcinogenesis and is negatively regulated by miR370. Mol Cancer Res 2013, 11(8): 834-844, https://doi. org/10.1158/1541-7786.mcr-13-0007.

11. Zhu Y., Jiang Q., Lou X., Ji X., Wen Z., Wu J., Tao H., Jiang T., He W., Wang C., Du Q., Zheng S., Mao J., Huang J. MicroRNAs up-regulated by CagA of Helicobacter pylori induce intestinal metaplasia of gastric epithelial cells. PLoS One 2012, 7(4): e35147, https://doi.org/10.1371/journal.pone.0035147.

12. Liu X., Ru J., Zhang J., Zhu L.H., Liu M., Li X., Tang H. miR-23a targets interferon regulatory factor 1 and modulates cellular proliferation and paclitaxel-induced apoptosis in gastric adenocarcinoma cells. PLoS One 2013, 8(6): e64707, https:// doi.org/10.1371/journal.pone.0064707.

13. Cadamuro A.C.T., Rossi A.F.T., Maniezzo N.M., Silva A.E. Helicobacter pylori infection: host immune response, implications on gene expression and microRNAs. World J Gastroenterol 2014; 20(6): 1424-1437, https://doi. org/10.3748/wjg.v20.i6.1424.

14. Ding S.Z., Goldberg J.B., Hatakeyama M. Helicobacter pylori infection, oncogenic pathways and epigenetic mechanisms in gastric carcinogenesis. Future Oncol 2010; 6(5): 851-862, https://doi.org/10.2217/fon.10.37.

15. Libânio D., Dinis-Ribeiro M., Pimentel-Nunes $P$. Helicobacter pylori and microRNAs: relation with innate immunity and progression of preneoplastic conditions. World J Clin Oncol 2015; 6(5): 111-132, https://doi.org/10.5306/wjco. v6.i5.111.

16. Wan X., Ding X., Chen S., Song H., Jiang H., Fang Y., Li P., Guo J. The functional sites of miRNAs and IncRNAs in gastric carcinogenesis. Tumour Biol 2015; 36(2): 521-532, https://doi.org/10.1007/s13277-015-3136-5.

17. Zhang B.G., Li J.F., Yu B.Q., Zhu Z.G., Liu B.Y., Yan M. microRNA-21 promotes tumor proliferation and invasion in gastric cancer by targeting PTEN. Oncol Rep 2012; 27(4): 1019-1026, https://doi.org/10.3892/or.2012.1645.

18. Li X., Zhang Y., Zhang H., Liu X., Gong T., Li M., Sun L., Ji G., Shi Y., Han Z., Han S., Nie Y., Chen X., Zhao Q., Ding J., Wu K., Daiming F. miRNA-223 promotes gastric cancer invasion and metastasis by targeting tumor suppressor EPB41L3. Mol Cancer Res 2011; 9(7): 824-833, https://doi. org/10.1158/1541-7786.mcr-10-0529.

19. Miao L., Liu K., Xie M., Xing Y., Xi T. miR-375 inhibits Helicobacter pylori-induced gastric carcinogenesis by blocking JAK2-STAT3 signaling. Cancer Immunol Immunother 2014; 63(7): 699-711, https://doi.org/10.1007/s00262-014-1550-y. 